\title{
The Impact of Violent Crime on Obesity
}

\author{
Lisa Stolzenberg*(D), Stewart J. D'Alessio and Jamie L. Flexon \\ Department of Criminology and Criminal Justice, Florida International University, Miami, FL 33199, USA; \\ dalessi@fiu.edu (S.J.D.); flexonj@fiu.edu (J.L.F.) \\ * Correspondence: stolzenb@fiu.edu
}

Received: 21 October 2019; Accepted: 4 December 2019; Published: 10 December 2019

\begin{abstract}
Dwelling in a violence-plagued neighborhood may amplify obesity by engendering psychological distress or by cultivating a sedentary, homebound lifestyle. This relationship is speculated to be especially relevant for black and Hispanic citizens because they are much more likely than whites to live in violence-beleaguered neighborhoods. Results from two multilevel analyses of 12,645 residents living in $34 \mathrm{New}$ York City neighborhoods show that, while the violent crime rate does not have a direct effect on obesity, it does condition the relationships between race, ethnicity, and obesity. As the violent crime rate rises in a neighborhood, the probability of both a black and Hispanic resident being obese increases, controlling for both individual and neighborhood factors. The BMI of black and Hispanic residents is also higher in neighborhoods beset by violence. These findings suggest that violent crime may be a salient but unappreciated factor in explaining both racial and ethnic differences in obesity.
\end{abstract}

Keywords: obesity; race; ethnicity; violent crime; multilevel analysis

\section{Introduction}

Research examining the differential access to various resources along racial and ethnic lines is ubiquitous. Certain things are now universally recognized; for example, black and Hispanic citizens are disparately impacted by the availability of supermarkets, healthy food sources, park areas, and walking trails. Such issues of environmental justice can have an obvious impact on health (Hilmers et al. 2012; Taylor et al. 2006). Blacks and Hispanics have higher infant death mortality rates and are more likely to be a victim of homicide and homicide by discharge of a firearm ( $\mathrm{Xu}$ et al. 2018). Considering this reality, it is not surprising that blacks and Hispanics are specifically and disproportionately represented among the obese compared to non-Hispanic whites (National Center for Health Statistics 2018).

What has not been well elucidated is whether exposure to and threat of violence in neighborhoods may influence obesity by further constricting avenues toward a healthy lifestyle or by engendering stress-induced obesity. Such a possibility deserves exploration, as the consequences of obesity can be grave. If there is a discernible nexus, not only are blacks and Hispanics victimized by violence directly more often, but it is reasonable to assume that dwelling in a violence-plagued neighborhood may amplify obesity and its consequences by fostering psychological distress or by cultivating a sedentary, homebound lifestyle. The effect of violent crime on obesity is expected to be especially relevant for black and Hispanic citizens, because they are disproportionately represented in violence-plagued neighborhoods as a direct result of residential segregation, and because they have a greater proclivity than whites to be victims of serious violent crime (Morgan and Truman 2018).

To evaluate the above, data are culled from NYC's 2012 and 2014 Community Health Survey and from other sources to explore whether the violent crime rate moderates the relationship between race, ethnicity, and obesity for 12,645 residents living in 34 New York City neighborhoods, net controls. Multilevel analyses are then performed. Prior to discussing the results, the extant literature, though limited, is presented. 


\section{Background}

Obesity remains a serious public health concern (Bassett and Perl 2004). Nearly 35\% of adult Americans (78.6 million Americans) ages 20 and older are obese (Ogden et al. 2014). This obesity problem is by no means isolated to the adult population. Childhood obesity in the U.S. has more than tripled since the 1970s (Fryar et al. 2014), with nearly 17\% of children considered to be obese (Ogden et al. 2014). Obesity is projected to rise in the immediate future. The number of adult Americans who are considered obese is expected to increase from $35 \%$ to around $42 \%$ by 2030 (Finkelstein et al. 2012).

Obesity is especially problematic for black Americans, as they are 1.4 times more likely than non-Hispanic whites to be obese (National Center for Health Statistics 2012). Blacks have the highest age-adjusted rate of obesity, at 47.8\%, whereas Hispanics are slightly less, at 42.5\% (Ogden et al. 2014). In contrast, non-Hispanic whites are 15 percentage points lower than blacks, at $32.6 \%$, and nearly 10 percentage points lower than Hispanics, regarding the likelihood of being obese. Similar patterns are evident for minority children and young adults. Analyzing data collected from the National Health and Nutrition Examination Survey (NHANES), Ogden et al. (2014) reports that both Hispanics and non-Hispanic black children between the ages of 2-19 have the highest rates of childhood obesity, $22.4 \%$ and $20.2 \%$ respectively, compared to $14.1 \%$ of Non-Hispanic whites in the same age range. In another important study, Scharoun-Lee et al. (2009) examined a nationally representative sample of 11,200 young adults with a mean age of 22 years and found that obesity prevalence was highest in minority children, particularly blacks and Hispanics, with the disparity increasing dramatically for these two groups from adolescence to young adulthood.

The health-related problems engendered directly from being obese are vast and profuse. Obesity is known to be associated strongly with cardiovascular diseases such as heart failure, stroke, and coronary heart disease (Nordestgaard et al. 2012). Additionally, obesity has a direct causal link to a variety of other diseases, such as hypertension, type-II diabetes, arthritis, sleep apnea, depression, and various types of cancer (Graves 2010). In the most extreme cases, individuals can lose their lives to this disease. (Masters et al. 2013) report that obesity is associated with nearly 1 in 5 U.S. deaths, which is more than three times previous estimates.

There are also monetary costs associated with obesity. The medical expenses resulting from an obese adolescent between the ages of 11 to 17 is approximately 1098 USD more per year than for a normal-weight adolescent in the same age range (Biener et al. 2014). Regarding adult obesity, Wang et al. (2015) report that adult obesity cost states nearly eight billion dollars a year in Medicaid programs. It is estimated that the total cost of health-related issues due to obesity in the U.S. is as much as 147 billion USD a year, or roughly $9 \%$ of all medical expenses paid out yearly (Finkelstein et al. 2009), with this cost expected to increase to upwards of 700 billion USD by 2030 (Wang et al. 2008).

Although a variety of factors are adduced in the literature to explain the racial and ethnic disparities in obesity (Baskin 2015), one causal factor that has not been fully explored is the potential effect of violent crime. This oversight is surprising when one considers that the fear of crime engenders psychological stress (Kliewer 2006), which, in turn, is associated with obesity (Moore and Cunningham 2012). The short-term reduction in anxiety, depression, and frustration among those living under chronic, stressful conditions often outweighs the associated concerns of unhealthy behaviors, such as overeating (Jackson et al. 2010). In fact, "Overeating is an effective, early, well-learned response to chronic environmental stressors that only strengthens over the life course" (Jackson et al. 2010, p. 937). Living in a violence-plagued neighborhood may also engender obesity by cultivating a more sedentary lifestyle, because people are less apt to be active and leave their homes when they are fearful of being criminally victimized (Bennett et al. 2007; Burdette et al. 2006; Gómez et al. 2004; Weir et al. 2006).

Despite these theoretical assertions, and some notable exceptions (Sandy et al. 2013), most prior research studies typically report only a weak association between violent crime and obesity (Black et al. 2010; Powell-Wiley et al. 2017; Sandy et al. 2011). There is also little research investigating whether violent crime moderates the relationship between race, ethnicity, and obesity. This dearth of research is problematic, as the effect of violent crime on obesity should be greater for black and 
Hispanic citizens, because they often are compelled to live in violence-plagued neighborhoods due to residential segregation (Massey 2004). This situation enhances the likelihood that a black or Hispanic resident will become a victim of a serious violent crime. To illustrate, the difference in likelihood of being a crime victim of homicide between blacks and whites is five to one (Lauritsen 2009). Moreover, even after exposure risk is considered, fear of crime is related positively to victimization risk (Stafford and Galle 1984). Further elevating the fear of crime among black citizens is that they tend to distrust the police. An analysis of combined data taken from Gallup polls conducted between 2011 to 2014 shows that, while $59 \%$ of white citizens have a great deal or quite a lot of confidence in the police, only $37 \%$ of black citizens do (Newport 2014). A negative view of the police has been shown to enhance a person's fear of crime (Dowler 2003). Taken together, the actual and perceived risks of living in high-crime neighborhoods while not trusting the authorities charged with protecting residents may cultivate obesity among particularly minority residents via induced stress and by constraining freedom of movement because of fear.

In this study, we use both survey and census data drawn from 34 Neighborhoods in NYC and a multilevel study design to ascertain the strength of the interaction between the race and ethnicity of the survey respondent and the violent crime rate on obesity, net the effects of both micro-level and macro-level control variables. Following the logic articulated above, we theorize that obesity is not determined entirely by a respondent's race, ethnicity or by the violent crime rate. Rather, a key determinate for predicting obesity is the interaction between a respondent's race, ethnicity, and a neighborhood's violent crime rate. The salience of these interactions hinges on the assumption that, if living in a violence-plagued neighborhood increases obesity, it should have an amplified effect on black and Hispanic residents, because they are much more likely than white residents to dwell in crime-ridden neighborhoods and to be victims of serious violent crimes. The primary objective of this study, then, is to test empirically whether a high violent crime rate conditions the relationships between race, ethnicity, and obesity.

\section{Methods}

\subsection{Data}

The micro-level demographic and health-related data analyzed in this study were obtained from the NYC Community Health Survey for 2012 and 2014 (New York City Department of Health and Mental Hygiene 2012, 2014). The NYC Community Health Survey employs a stratified sampling procedure to generate both citywide and neighborhood estimates for NYC residents. Survey respondents include non-institutionalized adults aged 18 or older, randomly selected from households having a cell phone. The sampling frame for each survey was constructed from a telephone number catalog provided by a private vendor. Computer-assisted telephone interviewing (CATI) was used to collect information from one adult in each household. These data are useful for our intentions because information on micro-level factors associated with a given respondent is provided along with geocoding information that identifies the respondent's United Hospital Fund (UHF) neighborhood. These geographic identifiers are employed to match respondents with the violent crime rate and with the other macro-level variables drawn from several sources for the 34 UHF neighborhoods. Because these geographic identifiers are no longer publicly available in the NYC Community Health Survey, we could not include additional years in this study.

Obesity was determined by an individual's BMI, which is calculated using the height and weight measures reported by respondents. We analyze two measures of obesity in this study. First, survey administrators coded the BMI scores into the appropriate categories for normal weight, overweight and obese. A person is overweight if he or she has a BMI of 25 to 29.9, whereas an obese individual is someone with a BMI greater than or equal to 30 . We divided BMI into two categories: $1=$ obese and $0=$ under, normal and overweight. We selected obese versus not obese as our first outcome measure, because self-reported BMI tends to be fraught with measurement error (Rothman 2008). 
The dichotomization of a mismeasured continuous variable helps to reduce the bias resulting from such mismeasurement (Gustafson and Le 2002). Approximately 27\% of the survey respondents in NYC had a BMI equal to or greater than 30. However, notwithstanding the potential problem with measurement error, we still felt it important to evaluate the effect of violence on BMI directly. If the effect of violence on both the dichotomous and interval measures of obesity are similar, it would help to enhance confidence in our findings.

The dummy coded race (black) and ethnicity (Hispanic) variables both represent the exogenous variables of theoretical interest. Blacks comprise $26 \%$ of the survey population, while Hispanics represent $31 \%$ of the respondents. The expectation is that if the violent crime rate moderates the relationships between race, ethnicity and obesity, the coefficient for the dummy coded race and ethnicity variables should be positive and statistically significant across the 34 UHF neighborhoods in the two multilevel analyses.

Several other demographic and economic variables were also incorporated into the analyses as statistical controls. The demographic variables include sex, age, marital status, education, employment status, and household income. There are also several control variables measuring the health status of the survey respondent. These variables include whether the respondent has high blood pressure, the general health status of the respondent, level of physical activity, average number of sodas consumed per day, alcohol consumption, smoking behavior, whether the respondent has health insurance, and whether the respondent has a mental illness. A dummy coded variable reflecting the survey year was also included in the study. Finally, the neighborhood variables used in the multilevel analyses were derived from a variety of sources. The neighborhood variable of theoretical interest is the violent crime rate and is measured as the number of reported violent index crimes (murder and non-negligent manslaughter, rape, robbery, and felony assault), divided by the neighborhood population and multiplied by 100,000 . The other contextual variables include the percent black population, percent female population, percent Hispanic population, unemployment rate, and neighborhood poverty level. Tables 1 and 2 report the coding schemes and descriptive statistics for all the micro and macro-level variables used in the analyses.

Table 1. Description of respondent variables $(\mathrm{N}=12,645)$.

\begin{tabular}{|c|c|c|c|}
\hline Variable & Proportion (M) & SD & Coding \\
\hline Obesity & 0.27 & 0.45 & $1=\mathrm{BMI} \geq 30,0=\mathrm{BMI}<30$ \\
\hline BMI & 27.52 & 6.11 & BMI (range 3.86-99.16) \\
\hline Black & 0.26 & 0.44 & $1=$ black non-Hispanic, $0=$ white non-Hispanic \\
\hline Hispanic & 0.31 & 0.46 & $1=$ Hispanic, $0=$ white non-Hispanic \\
\hline Female & 0.58 & 0.49 & $1=$ female $0=$ male \\
\hline Age $25-44$ & 0.31 & 0.46 & $1=25-44,0=18-24$ \\
\hline Age 45-64 & 0.39 & 0.49 & $1=45-64,0=18-24$ \\
\hline Age $65+$ & 0.25 & 0.43 & $1=65+, 0=18-24$ \\
\hline Divorced/separated & 0.20 & 0.40 & $1=$ divorced $/$ separated, $0=$ married \\
\hline Widowed & 0.10 & 0.29 & $1=$ widowed, $0=$ married \\
\hline Never married & 0.29 & 0.45 & $1=$ never married, $0=$ married \\
\hline Less than high school & 0.14 & 0.35 & $1=$ less than high school, $0=$ college graduate \\
\hline High school graduate & 0.22 & 0.41 & $1=$ high school graduate, $0=$ college graduate \\
\hline Some college & 0.22 & 0.41 & $1=$ some college $0=$ college graduate \\
\hline Unemployed & 0.08 & 0.27 & $1=$ unemployed, $0=$ employed \\
\hline Not in labor force & 0.35 & 0.48 & $1=$ not in labor force, $0=$ employed \\
\hline Household annual income & 2.92 & 1.49 & $1=<100 \%$ FPL, $2=100-199 \%$ FPL, $3=200-399 \%$ FPL, $4=400-599 \%$ FPL, $5=600+\%$ FPL \\
\hline High blood pressure & 0.35 & 0.48 & $1=$ told by health professional that respondent has high blood pressure, $0=$ otherwise \\
\hline General health & 2.65 & 1.14 & $1=$ excellent, $2=$ very good, $3=$ good, $4=$ fair, $5=$ poor \\
\hline Physical activity & 1.94 & 0.83 & $1=$ very active, $2=$ somewhat active, $3=$ not very active, $4=$ not active at all \\
\hline Daily sodas & 0.28 & 0.90 & Average number of sodas per day (excludes diet sodas and seltzer) \\
\hline Heavy drinker & 0.06 & 0.23 & $1=>2$ alcohol drinks per day for men and $>1$ for women, $0=$ otherwise \\
\hline Smoker & 0.14 & 0.35 & $1=$ current smoker, $0=$ past or non-smoker \\
\hline Health insurance & 0.89 & 0.32 & $1=$ health insurance coverage, $0=$ no coverage \\
\hline Mental illness & 0.03 & 0.17 & $\begin{array}{c}1=\text { told by health professional that respondent has bipolar disorder, mania, psychosis, } \\
\text { or schizophrenia; } 0=\text { otherwise }\end{array}$ \\
\hline Year 2014 & 0.52 & 0.50 & $1=2014$ survey, $0=2012$ survey \\
\hline
\end{tabular}

Note. New York City Department of Health and Mental Hygiene. New York City Department of Health and Mental Hygiene $(2012,2014)$; public use datasets accessed on 1 February 2019. For additional information on the Community Health Survey, visit http://www1.nyc.gov/site/doh/data/data-sets/community-health-survey.page. 
Table 2. Description of UHF neighborhood variables $(\mathrm{N}=34)$.

\begin{tabular}{|c|c|c|c|}
\hline Variable & $\mathbf{M}$ & SD & Definition \\
\hline Violent crime rate & 494.20 & 251.92 & $\begin{array}{l}\text { Number of violent index crimes reported in } 2012 \text {, divided by the } \\
\text { UHF neighborhood population, and multiplied by 100,000. Violent } \\
\text { index crimes include murder and non-negligent manslaughter, rape, } \\
\text { robbery, and felony assault. }\end{array}$ \\
\hline Percent black & 23.67 & 23.18 & Percent of the population that is black or African American. \\
\hline Percent female & 52.11 & 2.01 & Percent of the population that is female. \\
\hline Percent Hispanic & 27.10 & 17.74 & Percent of the population that is Hispanic. \\
\hline Unemployment rate & 6.46 & 1.91 & Percent of civilian labor force that is unemployed. \\
\hline $\begin{array}{l}\text { Neighborhood } \\
\text { poverty }\end{array}$ & 2.43 & 0.85 & $\begin{array}{c}\text { Mean score } 1=0-9 \% \text { (low poverty), } 2=10-19 \%, 3=20-29 \%, \\
4=30-99 \% \text { (high poverty) }\end{array}$ \\
\hline
\end{tabular}

Notes. Violent crime rates were obtained from the NYC Police Department, Historical NYC Crime Data, Seven Major Felony Offenses by Precinct 2000-17. Precincts were merged into UHF neighborhoods based on their zip code. When more than one precinct was included in a UHF neighborhood, the number of reported violent crimes was added. Percent black, percent female, percent Hispanic, and the unemployment rate were derived from the U.S. Census Bureau, 2010-2014 American Community Survey 5-Year Estimates. Neighborhood poverty mean scores were calculated from the New York City Department of Health and Mental Hygiene. New York City Department of Health and Mental Hygiene (2012, 2014), public use datasets accessed on February 1, 2019. The scale is based on the percent of zip code population living below 100\% FPL per American Community Survey, 2009-2013.

\subsection{Multilevel Analyses}

A Hierarchical Generalized Linear Model (HGLM), which uses a penalized quasi-likelihood (PQL) procedure to generate parameter estimates, was employed to undertake the analysis with the dichotomous dependent variable measuring obesity (Breslow and Clayton 1993). We used a hierarchical linear model to analyze the interval BMI-dependent variable. Our use of a multilevel methodology to determine whether the violent crime rate conditions the relationships between race, ethnicity, and obesity is advantageous for several reasons and the methodology has been employed with success in prior studies on obesity (Cohen et al. 2006; Robert and Reither 2005). First, because multilevel models explicitly recognize the clustering of individuals within higher-level units such as neighborhoods, they avoid violating the assumption of statistical independence among observations. Second, hierarchical models are helpful for estimating cross-level effects, since all estimates are adjusted for the covariates regardless of whether they are measured at the individual or contextual level. Finally, hierarchical models not only partition the variance between levels, but they also can statistically separate the variance of the individual-level parameters from sampling variance. The inability to factor out the sampling variance when data are hierarchical results in an underestimate of the explanatory power of the contextual variables.

Except for the intercept and the respondent's race and ethnicity, we model all the other respondent variables as fixed or constrained to be the same for all the neighborhoods because between-neighborhood variation in these parameters is not of interest in this study. The intercept and the respondent's race and ethnicity variables are treated as random variables, given that we are interested in determining whether variation in the violent crime rate affects the likelihood of obesity and whether the respondent's race and ethnicity conditions this relationship. The micro-level independent variables were centered by subtracting their grand means, so that the mean of each variable is zero across all cases. This procedure is useful as it tends to attenuate multicollinearity and because it facilitates the interpretation of the variable when it becomes the dependent variable in the neighborhood-level model. For example, centering allows the race coefficient to be interpreted as the average gap in obesity between black and white residents living in the 34 neighborhoods. Moreover, because we permit the intercept and the race and ethnicity variables to vary across neighborhoods, we can model any observable differences in the likelihood of obesity with the violent crime rate and the other contextual variables. This variability between UHF neighborhoods is the outcome that is explained in the between-neighborhood models. The results generated in the hierarchical generalized linear model, which is appropriate for a dichotomous dependent variable, are reported in Table 3. 
Table 3. Hierarchical generalized linear model estimating the likelihood of obesity.

\begin{tabular}{|c|c|c|}
\hline & Coefficient & SE \\
\hline \multicolumn{3}{|l|}{ Obesity probability differential } \\
\hline Intercept & $-1.091^{* * *}$ & 0.046 \\
\hline Violent crime rate & $-0.051 \times 10^{-2}$ & $0.028 \times 10^{-2}$ \\
\hline Percent black & 0.002 & 0.004 \\
\hline Percent female & -0.019 & 0.029 \\
\hline Percent Hispanic & -0.002 & 0.004 \\
\hline Unemployment rate & 0.024 & 0.045 \\
\hline Neighborhood poverty & 0.111 & 0.084 \\
\hline \multicolumn{3}{|l|}{ Black-white obesity differential } \\
\hline Intercept & $0.475^{* * *}$ & 0.095 \\
\hline Violent crime rate & $0.113 \times 10^{-2 *}$ & $0.056 \times 10^{-2}$ \\
\hline Percent black & -0.005 & 0.009 \\
\hline Percent female & 0.060 & 0.060 \\
\hline Percent Hispanic & -0.002 & 0.009 \\
\hline Unemployment rate & -0.033 & 0.090 \\
\hline Neighborhood poverty & 0.079 & 0.172 \\
\hline \multicolumn{3}{|l|}{ Hispanic-white obesity differential } \\
\hline Intercept & $0.365^{* * *}$ & 0.090 \\
\hline Violent crime rate & $0.114 \times 10^{-2 *}$ & $0.053 \times 10^{-2}$ \\
\hline Percent black & -0.006 & 0.008 \\
\hline Percent female & 0.058 & 0.054 \\
\hline Percent Hispanic & -0.011 & 0.008 \\
\hline Unemployment rate & -0.007 & 0.085 \\
\hline Neighborhood poverty & 0.019 & 0.154 \\
\hline Female & $0.154^{* * *}$ & 0.045 \\
\hline Age $25-44$ & $0.307^{* *}$ & 0.108 \\
\hline Age $45-64$ & $0.371^{* * *}$ & 0.110 \\
\hline Age $65+$ & -0.113 & 0.122 \\
\hline Divorced/separated & -0.107 & 0.060 \\
\hline Widowed & $-0.211^{* *}$ & 0.083 \\
\hline Never married & 0.085 & 0.055 \\
\hline Less than high school & $0.249 * * *$ & 0.077 \\
\hline High school graduate & $0.295^{* * *}$ & 0.064 \\
\hline Some college & $0.330 * * *$ & 0.061 \\
\hline Unemployed & 0.083 & 0.080 \\
\hline Not in labor force & $-0.117 *$ & 0.058 \\
\hline Household annual income & -0.015 & 0.020 \\
\hline High blood pressure & $0.807^{* * *}$ & 0.049 \\
\hline General health & $0.219 * * *$ & 0.023 \\
\hline Physical activity & $0.418^{* * *}$ & 0.026 \\
\hline Daily sodas & -0.006 & 0.024 \\
\hline Heavy drinker & -0.081 & 0.100 \\
\hline Smoker & $-0.245^{* * *}$ & 0.064 \\
\hline Health insurance & 0.057 & 0.070 \\
\hline Mental illness & 0.265 * & 0.120 \\
\hline Year 2014 & -0.011 & 0.043 \\
\hline
\end{tabular}

Notes. ${ }^{*} p \leq 0.05,{ }^{* *} p \leq 0.01,{ }^{* * *} p \leq 0.001$ (two-tailed tests). Results for population-average model.

\section{Hierarchical Generalized Linear Results}

A visual inspection of Table 3 reveals that, at the resident level, there are several demographic and health variables that are statistically noteworthy in the equation. Compared to non-Hispanic white residents, black and Hispanic residents have a higher probability of being obese. Survey respondents who are female, ages 25-64, not widowed, less educated, and in the labor force, are also more likely to be obese. In addition, many of the health-related variables included in the equation are of substantive importance. These variables include high blood pressure, general health status, physical activity, 
smoker, and mental illness. The likelihood of obesity is lower for people with good general health status, who partake regularly in physical activities, and smokers. The likelihood of obesity also tends to be higher for people with high blood pressure and for residents who have been told by their healthcare professional that they have a mental illness.

Table 3 also shows the results for the effects of the neighborhood-level variables on the likelihood of obesity. If violence is engendering obesity, there is a natural expectation that the likelihood of a resident being obese will be higher in neighborhoods plagued by violent crime. However, despite our assumption, findings reveal a nonconsequential effect of the violent crime rate on the general likelihood of obesity. The small and non-statistically significant effect of the violent crime rate variable in the model can be interpreted as evidence against the position that violent crime is contributing to obesity by fostering resident stress or by cultivating a sedentary lifestyle. A visual examination of Table 3 also shows that none of the aggregate variables have any predictive power in the model.

The results for the black-white and Hispanic-white obesity differentials are also reported in Table 3. An examination of these models reveals that there is a consequential effect of the violent crime rate on racial and ethnic differences in obesity. Our finding of the moderating effect of the violent crime rate on the black-white and Hispanic-white obesity differentials supports the position that being exposed to violent crime has a greater influence on obesity among black and Hispanic residents. It is important to recognize that just because blacks, Hispanics and whites might live in the same neighborhood plagued by violent crime does not necessarily mean that these racial and ethnic groups have the same likelihood of victimization. Blacks and Hispanics are more apt than whites to be seriously victimized by criminals. The results displayed in Table 3 also reveal that none of the other aggregate variables have any substantive moderating effects.

\section{Hierarchical Linear Results}

We next employed hierarchical linear modeling to discern whether the violence rate influences the BMI of NYC residents while accounting for other factors theorized to be related to obesity. This statistical procedure is appropriate for analyzing an interval dependent variable. If the violence rate does condition the effect of race and ethnicity on obesity, we would expect the violent crime rate to influence the black-white and Hispanic-white BMI differentials in the positive direction across the UHF neighborhoods.

The results reported in Table 4 show that the violent crime rate has a statistically significant positive effect on both the black-white and Hispanic-white BMI differentials. As the violent crime rate increases in UHF neighborhoods, the difference in BMI between blacks and whites and between Hispanics and whites grows progressively larger. One can interpret these findings, when coupled with the results reported in Table 3 for the dichotomous measure of obesity, as compelling evidence supporting the assertion that violent crime is an important factor in explicating both racial and ethnic differences in obesity.

The effects for most of the control variables are also compatible with those originally reported in Table 3. Only a few variables show different effects when BMI is used as the dependent variable. Two contextual variables are now statistically substantive. Both percent black and percent female show a noteworthy effect on the black-white obesity differential. The sex of the respondent now has a negative influence on BMI. Women are more apt to have a higher BMI than men. The coefficients for not in the labor force and for mental illness are also no longer statistically significant, although they both had relatively weak effects in the initial equation reported in Table 3. 
Table 4. Hierarchical linear model estimating BMI.

\begin{tabular}{|c|c|c|}
\hline & Coefficient & SE \\
\hline \multicolumn{3}{|l|}{ Obesity probability differential } \\
\hline Intercept & $27.675^{* * *}$ & 0.115 \\
\hline Violent crime rate & $-0.135 \times 10^{-2}$ & $0.073 \times 10^{-2}$ \\
\hline Percent black & 0.002 & 0.011 \\
\hline Percent female & -0.027 & 0.076 \\
\hline Percent Hispanic & -0.003 & 0.011 \\
\hline Unemployment rate & 0.107 & 0.116 \\
\hline Neighborhood poverty & 0.191 & 0.217 \\
\hline \multicolumn{3}{|l|}{ Black-white obesity differential } \\
\hline Intercept & $1.838^{* * *}$ & 0.211 \\
\hline Violent crime rate & $0.289 \times 10^{-2 *}$ & $0.123 \times 10^{-2}$ \\
\hline Percent black & $-0.041 *$ & 0.019 \\
\hline Percent female & $0.401^{* *}$ & 0.136 \\
\hline Percent Hispanic & -0.012 & 0.019 \\
\hline Unemployment rate & 0.011 & 0.201 \\
\hline Neighborhood poverty & 0.246 & 0.392 \\
\hline \multicolumn{3}{|l|}{ Hispanic-white obesity differential } \\
\hline Intercept & $1.179^{* * *}$ & 0.194 \\
\hline Violent crime rate & $0.226 \times 10^{-2 *}$ & $0.111 \times 10^{-2}$ \\
\hline Percent black & -0.020 & 0.017 \\
\hline Percent female & 0.223 & 0.114 \\
\hline Percent Hispanic & -0.033 & 0.016 \\
\hline Unemployment rate & -0.020 & 0.182 \\
\hline Neighborhood poverty & 0.272 & 0.328 \\
\hline Female & $-0.418^{* * *}$ & 0.106 \\
\hline Age $25-44$ & $1.595^{* * *}$ & 0.242 \\
\hline Age $45-64$ & $1.782 * * *$ & 0.249 \\
\hline Age 65+ & 0.310 & 0.275 \\
\hline Divorced/separated & 0.021 & 0.143 \\
\hline Widowed & $-0.458 *$ & 0.198 \\
\hline Never married & 0.067 & 0.131 \\
\hline Less than high school & $0.723^{* * *}$ & 0.189 \\
\hline High school graduate & $0.671^{* * *}$ & 0.152 \\
\hline Some college & $0.762^{* * *}$ & 0.144 \\
\hline Unemployed & 0.028 & 0.196 \\
\hline Not in labor force & -0.087 & 0.137 \\
\hline Household annual income & 0.008 & 0.047 \\
\hline High blood pressure & $2.249^{* * *}$ & 0.121 \\
\hline General health & $0.561 * * *$ & 0.054 \\
\hline Physical activity & $1.177^{* * *}$ & 0.065 \\
\hline Daily sodas & -0.099 & 0.057 \\
\hline Heavy drinker & -0.279 & 0.222 \\
\hline Smoker & $-0.570^{* * *}$ & 0.151 \\
\hline Health insurance & 0.275 & 0.168 \\
\hline Mental illness & 0.386 & 0.305 \\
\hline Year 2014 & -0.021 & 0.101 \\
\hline
\end{tabular}

Notes. ${ }^{*} p \leq 0.05,{ }^{* *} p \leq 0.01,{ }^{* * *} p \leq 0.001$ (two-tailed tests). Results for fixed-effects model.

\section{Discussion}

Although a sizable body of quantitative research on the relationships between race, ethnicity, and obesity has accrued in recent years, the underlying causal factors responsible for the observed racial and ethnic disparities in obesity remains elusive. We argued here that the violent crime rate might not have a direct effect on obesity, as theorized in previous research. Rather, it is plausible that violent crime moderates the relationship between race, ethnicity, and obesity, as blacks and Hispanics have a greater proclivity to live in violence-plagued neighborhoods due to residential segregation. Black and Hispanic 
residents are also much more apt than whites to be victims of serious violent crime. We proffered that this thesis could be tested empirically by analyzing multilevel data to ascertain whether the violent crime rate explains racial and ethnic differences in obesity. Thus, black and Hispanic residents should be more likely to be obese and have a higher BMI in neighborhoods where the violent crime rate is more pronounced, controlling for other relevant factors related to obesity.

Findings from our multilevel analysis show that, controlling for several theoretically relevant variables, the violent crime rate has a null effect on the likelihood that a person living in one of the 34 neighborhoods in NYC will be obese or have a higher BMI. Residents in neighborhoods with higher levels of violent crime are not more inclined to be obese. However, while there is not a direct relationship between neighborhood violence and obesity, the violent crime rate does appear to condition the relationships between a resident's race, ethnicity and the likelihood that he or she will be obese. In neighborhoods with a high violent crime rate, we find that black and Hispanic residents are more apt to be obese and have a higher BMI. These effects persist despite the inclusion of both micro-level and macro-level predictors of obesity.

Our results, showing that neighborhood violence amplifies obesity among black and Hispanic residents, underscore the critical importance of considering the possibility that contextual variables have a moderating effect on micro-level variables such as race and ethnicity in explaining obesity. A comprehensive understanding of the racial and ethnic disparities in obesity necessitates the simultaneous consideration of individual and environmental factors, because they may interact with each other to create a situation that produces obesity. The statistically noteworthy effects between the violent crime rate and racial and ethnic differences in obesity have important consequences for future research, as many previous studies on obesity neglected to contemplate the possibility that the violent crime rate influenced blacks and Hispanics differently than whites. Our findings show that the failure to explicitly consider these relationships can be misleading and detract from our understanding of the principal causes of racial and ethnic differences in obesity.

\section{Limitations and Recommendations}

A couple of caveats should be contemplated when evaluating the import of our findings. First, although the data gathered by NYC furnished us with an excellent opportunity to investigate the effect of the violent crime rate on racial and ethnic differences in obesity, a question remains as to whether our findings are applicable to other cities. Because we focused on neighborhoods situated in a single city, it is of vital importance for other researchers to conduct similar studies in other cities. If these studies produce similar results, then confidence in the moderating effect of violent crime on the relationships between race, ethnicity, and obesity will be enhanced. Second, despite our inclusion of extensive controls for predicting obesity and BMI, other salient factors may remain inadequately measured or even unspecified. For instance, although our analyses show that the violent crime rate conditions the relationships between race, ethnicity, and obesity, the precise mechanisms linking these variables remain elusive. It is conceivable that stress influences obesity. For example, as violence rises in a neighborhood, black and Hispanic citizens may increasingly perceive that they have a greater likelihood of becoming a crime victim. Yet, because of data constraints, we are unable to directly measure fear of crime among black, Hispanic and white residents in our study. Consequently, such theorizing remains merely speculative in the absence of attitudinal survey data.

Adequate access to venues and opportunities for making healthy lifestyle choices that attenuate obesity are diminished for blacks and Hispanics, as initially pointed out. We did evaluate daily physical activity and other variables, such as whether the respondent drank daily sodas, but this may not be enough for adequate controls in the analysis. Future research may wish to rectify this problem, although other datasets with this type of information would need to be identified. 


\section{Conclusions}

Notwithstanding these shortcomings, our results speak to the long-running debate about the underlying causes of the racial/ethnic differences in obesity in the U.S. The results produced from our multilevel analyses support the hypothesis that race and ethnic differences in obesity are dependent to a noteworthy degree on the amount of violence occurring in a neighborhood. Explicit acknowledgment of the conditioning effect of neighborhood violence on racial and ethnic differences in obesity suggests a potential focus on the adverse consequences of residential segregation because residential segregation makes it much more likely that black and Hispanic families will be channeled into violence-plagued neighborhoods. Additionally, because of economic and social advantages, white families are often afforded the opportunity to move out of violence-plagued neighborhoods, further aggravating a bad situation (Liska and Bellair 1995).

In sum, our findings suggest that race and ethnic differences in obesity will likely persist, so long as residential segregation compels black and Hispanic citizens to live in violence-plagued neighborhoods. Without a concerted effort to recognize the broad and long-term consequences of such environmental injustices, an effective policy aimed at ameliorating such risk will not be forthcoming. We believe our findings demonstrate the need to extend research examining environmental justice concerns to include the impact of violent crime on disproportionately impacted citizens.

Author Contributions: All authors (L.S., S.J.D. and J.L.F.) contributed to study conception and design, material preparation, data collection and analysis, and manuscript drafting and revision. All authors read and approved the final manuscript.

Funding: This research received no external funding.

Conflicts of Interest: The authors declare no conflict of interest.

\section{References}

Baskin, Monica L. 2015. Understanding and addressing racial/ethnic disparities in obesity. In Race and Social Problems: Restructuring Inequality. Edited by Ralph Bangs and Larry E. Davis. New York: Springer, pp. 247-65.

Bassett, Mary T., and Sarah Perl. 2004. Obesity: The public health challenge of our time. American Journal of Public Health 94: 1477. [CrossRef] [PubMed]

Bennett, Gary G., Lorna H. McNeill, Kathleen Y. Wolin, Dustin T. Duncan, Elaine Puleo, and Karen M. Emmons. 2007. Safe to walk? Neighborhood safety and physical activity among public housing residents. PLoS Medicine 4: 1599-606. [CrossRef] [PubMed]

Biener, Adam I., Chad Meyerhoefer, and John Cawley. 2014. Estimating the Medical Care Costs of Youth Obesity in the Presence of Proxy Reporting Error. Unpublished manuscript, preliminary draft.

Black, Jennifer L., James Macinko, L. Beth Dixon, and George E. Fryer Jr. 2010. Neighborhoods and obesity in New York City. Health \& Place 16: 489-99.

Breslow, N. E., and D. G. Clayton. 1993. Approximate inference in generalized linear mixed models. Journal of the American Statistical Association 88: 9-25.

Burdette, Hillary L., Thomas A. Wadden, and Robert C. Whitaker. 2006. Neighborhood safety, collective efficacy, and obesity in women with young children. Obesity 14: 518-25. [CrossRef]

Cohen, Deborah, Brian Finch, Aimee Bower, and Narayan Sastry. 2006. Collective efficacy and obesity: The potential influence of social factors on health. Social Science $\mathcal{E}$ Medicine 62: 769-78.

Dowler, Kenneth. 2003. Media consumption and public attitudes toward crime and justice: The relationship between fear of crime, punitive attitudes, and perceived police effectiveness. Journal of Criminal Justice and Popular Culture 10: 109-26.

Finkelstein, Eric A., Justin G. Trogdon, Joel W. Cohen, and William Dietz. 2009. Annual medical spending attributable to obesity: Payer-and service-specific estimates. Health Affairs 28: w822-w831. [CrossRef]

Finkelstein, Eric A., Olga A. Khavjou, Hope Thompson, Justin G. Trogdon, Liping Pan, Bettylou Sherry, and William Dietz. 2012. Obesity and severe obesity forecasts through 2030. American Journal of Preventive Medicine 42: 563-70. [CrossRef] 
Fryar, Cheryl D., Margaret D. Carroll, and Cynthia L. Ogden. 2014. Prevalence of Overweight and Obesity among Children and Adolescents: United States, 1963-1965 through 2011-2012; Hyattsville: National Center for Health Statistics.

Gómez, Jorge E., Beth Ann Johnson, Martha Selva, and James F. Sallis. 2004. Violent crime and outdoor physical activity among inner-city youth. Preventive Medicine 39: 876-81. [CrossRef]

Graves, Barbara W. 2010. The obesity epidemic: Scope of the problem and management strategies. Journal of Midwifery \& Women's Health 55: 568-78.

Gustafson, Paul, and Nhu D. Le. 2002. Comparing the effects of continuous and discrete covariate mismeasurement, with emphasis on the dichotomization of mismeasured predictors. Biometrics 58: 878-87. [CrossRef] [PubMed]

Hilmers, Angela, David C. Hilmers, and Jayna Dave. 2012. Neighborhood disparities in access to healthy foods and their effects on environmental justice. American Journal of Public Health 102: 1644-54. [CrossRef] [PubMed]

Jackson, James S., Katherine M. Knight, and Jane A. Rafferty. 2010. Race and unhealthy behaviors: Chronic stress, the HPA axis, and physical and mental health disparities over the life course. American Journal of Public Health 100: 933-39. [CrossRef]

Kliewer, Wendy. 2006. Violence exposure and cortisol responses in urban youth. International Journal of Behavioral Medicine 13: 109-20. [CrossRef]

Lauritsen, Janet L. 2009. Criminal victimization in the United States: Trends and patterns of risk. In Toward a Safer Society; Edited by Linda L. Sabbadini, Maria Giuseppina Muratore and Giovanna Tagliacozzo. Roma: Istituto Nazionale de Statistica, pp. 67-82.

Liska, Allen E., and Paul E. Bellair. 1995. Violent crime rates and racial composition: Convergence over time. American Journal of Sociology 101: 578-610. [CrossRef]

Massey, Douglas S. 2004. Segregation and stratification: A biosocial perspective. Du Bois Review 1: 7-25. [CrossRef]

Masters, Ryan K., Eric N. Reither, Daniel A. Powers, Claire Yang, Andrew E. Burger, and Bruce G. Link. 2013. The impact of obesity on U.S. mortality levels: The importance of age and cohort factors in population estimates. American Journal of Public Health 103: 1895-901. [CrossRef]

Moore, Carla J., and Solveig A. Cunningham. 2012. Social position, psychological stress, and obesity: A systematic review. Journal of the Academy of Nutrition and Dietetics 112: 518-26. [CrossRef]

Morgan, Rachel E., and Jennifer L. Truman. 2018. Criminal Victimization, 2017; Washington, DC: Bureau of Justice Statistics.

National Center for Health Statistics. 2012. Health, United States, 2011: With Special Feature on Socioeconomic Status and Health; Hyattsville: U.S. Department of Health and Human Services.

National Center for Health Statistics. 2018. Health, United States, 2017; Hyattsville: U.S. Department of Health and Human Services.

New York City Department of Health and Mental Hygiene. 2012. Community Health Survey 2012; public use dataset accessed on 1 February 2019.

New York City Department of Health and Mental Hygiene. 2014. Community Health Survey 2014; public use dataset accessed on 1 February 2019.

Newport, Frank. 2014. Gallup Review: Black and White Attitudes toward Police. Available online: http://www.gallup. com/poll/175088/gallup-review-black-white-attitudes-toward-police.aspx (accessed on 5 December 2019).

Nordestgaard, Børge G., Tom M. Palmer, Marianne Benn, Jeppe Zacho, Anne Tybjaerg-Hansen, George Davey Smith, and Nicholas J. Timpson. 2012. The effect of elevated body mass index on ischemic heart disease risk: Causal estimates from a Mendelian randomisation approach. PLoS Med 9: e1001212. [CrossRef]

Ogden, Cynthia L., Margaret D. Carroll, Brian K. Kit, and Katherine M. Flegal. 2014. Prevalence of childhood and adult obesity in the United States, 2011-2012. JAMA 311: 806-14. [CrossRef] [PubMed]

Powell-Wiley, Tiffany M., Kari Moore, Norrina Allen, Richard Block, Kelly R. Evenson, Mahasin Mujahid, and Ana V. Diez Roux. 2017. Associations of neighborhood crime and safety and with changes in body mass index and waist circumference: The multi-ethnic study of Atherosclerosis. American Journal of Epidemiology 186: 280-88. [CrossRef] [PubMed]

Robert, Stephanie A., and Eric N. Reither. 2005. A multilevel analysis of race, community disadvantage, and body mass index among adults in the U.S. Social Science \& Medicine 59: 2421-34.

Rothman, Kenneth J. 2008. BMI-related errors in the measurement of obesity. International Journal of Obesity 32: S56-S59. [CrossRef] [PubMed] 
Sandy, Robert, Gilbert Liu, John Ottensmann, Rusty Tchernis, Jeffrey Wilson, and O. T. Ford. 2011. Studying the child obesity epidemic with natural experiments. In Economic Aspects of Obesity. Edited by Michael Grossman and Naci Mocan. Chicago: University of Chicago Press, pp. 181-221.

Sandy, Robert, Rusty Tchernis, Jeffrey Wilson, Gilbert Liu, and Xilin Zhou. 2013. Effects of the built environment on childhood obesity: The case of urban recreational trails and crime. Economics \& Human Biology 11: 18-29.

Scharoun-Lee, Melissa, Linda S. Adair, Jay S. Kaufman, and Penny Gordon-Larsen. 2009. Obesity, race/ethnicity and the multiple dimensions of socioeconomic status during the transition to adulthood: A factor analysis approach. Social Science E Medicine 68: 708-16.

Stafford, Mark C., and Omer R. Galle. 1984. Victimization rates, exposure to risk, and fear of crime. Criminology 22: 173-85. [CrossRef]

Taylor, Wendell C., Walker S. C. Poston, Lovell Jones, and M. Katherine Kraft. 2006. Environmental justice: obesity, physical activity, and healthy eating. Journal of Physical Activity $\mathcal{E}$ Health 3: S30-S54.

Wang, Y. Claire, John Pamplin, Michael W. Long, Zachary J. Ward, Steven L. Gortmaker, and Tatiana Andreyeva. 2015. Severe obesity in adults cost state medicaid programs nearly $\$ 8$ billion in 2013. Health Affairs 34: 1923-31. [CrossRef]

Wang, Youfa, May A. Beydoun, Lan Liang, Benjamin Caballero, and Shiriki K. Kumanyika. 2008. Will all Americans become overweight or obese? Estimating the progression and cost of the U.S. obesity epidemic. Obesity 16: 2323-30. [CrossRef]

Weir, Lori A., Debra Etelson, and Donald A. Brand. 2006. Parents' perceptions of neighborhood safety and children's physical activity. Preventive Medicine 43: 212-17. [CrossRef] [PubMed]

Xu, Jiaquan, Sherry L. Murphy, Kenneth D. Kochanek, Brigham Bastian, and Elizabeth Arias. 2018. Deaths: Final Data for 2016. National Vital Statistics Reports; Hyattsville: National Center for Health Statistics, Volume 67.

(C) 2019 by the authors. Licensee MDPI, Basel, Switzerland. This article is an open access article distributed under the terms and conditions of the Creative Commons Attribution (CC BY) license (http://creativecommons.org/licenses/by/4.0/). 